BMJ

Open

Gastroenterology

\title{
Complete colonoscopy: impact of patients' demographics and anthropometry on caecal intubation time
}

\author{
Adegboyega Akere, Jesse Abiodun Otegbayo
}

\begin{abstract}
Background and aim: Factors that affect caecal intubation during colonoscopy include age and sex of the patient, quality of bowel preparation, prior abdominal or pelvic surgery and pelvic inflammatory disease, among others. The aim of this prospective study was to evaluate the effects of patients' demography such as age and sex, as well as anthropometry (height, weight and body mass index (BMI)) on caecal intubation time (CIT).
\end{abstract}

Received 2 January 2016 Revised 29 February 2016 Accepted 17 March 2016

Patients and methods: All consecutive patients referred for colonoscopy over a period of 6 months were recruited into the study. Prior to the procedure,
Department of Medicine, College of Medicine, University of Ibadan/ University College Hospital, Ibadan, Nigeria

\section{Correspondence to} Dr Adegboyega Akere; adeakere@yahoo.co.uk patients' demographic data as well as history of prior abdominal or pelvic surgery were recorded. The height and weight of each patient were taken, and the BMI calculated. CIT was measured from the time of insertion of the colonoscope into the anal canal to the time when the base of the caecum was intubated.

Results: A total of 167 patients comprising 99 $(59.3 \%)$ males and $68(40.7 \%)$ females were studied. The mean CIT of the procedures was 912.5 $\pm 477.1 \mathrm{~s}$ with a range of $180-3180 \mathrm{~s}$. It was more prolonged in patients older than 65 years of age, in males and in those with prior abdominal/pelvic surgery, although no significant difference was observed among the groups. Multivariate logistic regression analysis showed that increased $\mathrm{BMI}$ and non-usage of additional manoeuvres independently reduced CIT.

Conclusions: Older age, male gender, prior abdominal/pelvic surgery, use of additional manoeuvres and lower BMI were found to prolong CIT.

\section{INTRODUCTION}

Complete colonoscopy is important so as to detect and, in some instances, treat as much as possible colorectal abnormalities. ${ }^{1}$ Caecal intubation time (CIT) during colonoscopy is the time it takes from anal insertion to the time to insert the tip of the colonoscope in the caecum. It is often used to define complete colonoscopy, assess the experience of

\section{Summary box}

What is already know about this subject?

- Female gender is associated with a prolonged caecal intubation time.

- Prior abdominal hysterectomy prolongs caecal intubation time.

- Lower body mass index (BMI) is associated with prolongation of caecal intubation time.

What are the new findings in this study?

- Caecal intubation time appears longer in Africans probably due to the longer colon length in Africans compared with Caucasians.

- Male gender is associated with prolonged caecal intubation time.

- Prior exploratory laparotomy and appendectomy are associated with shorter caecal intubation time.

- Correlation between lower BMI and prolonged caecal intubation time is not linear, because patients with a BMl of $30-39 \mathrm{~kg} / \mathrm{m}^{2}$ had a higher CIT compared to those with a BMI of $25-29.9 \mathrm{~kg} / \mathrm{m}^{2}$.

How might it impact on clinical practice in the foreseeable future?

- The findings in our study probably showed that racial and geographical differences might also affect caecal intubation time, and this needs to be taken into consideration during colonoscopy.

the colonoscopist, as well as a measure of difficult colonoscopy. ${ }^{2}$ Difficult colonoscopy may be associated with a painful and unpleasant experience on the part of the patient. It may also prolong the procedure, necessitate the need for more sedation and analgesia for the patient, as well as increase the risks of complications. Several factors have been observed to affect CIT during colonoscopy. Among these are age and sex of the patient, quality of bowel preparation, prior abdominal or pelvic surgery, especially hysterectomy, pelvic inflammatory disease as well as presence of colonic diverticuli and 
constipation in the patient. ${ }^{3-5}$ Knowledge of these factors is important because it may assist the endoscopist to predict which patient is likely to have a prolonged procedure and, as such, plan accordingly with respect to the type of sedation and analgesia to use, as well as schedule such patient with a more experienced endoscopist. To the best of our knowledge, this is the first report of CIT in Nigeria. The aim of this prospective study was to evaluate the effects of patients' demography such as age and sex, as well as anthropometry on CIT.

\section{PATIENTS AND METHODS}

This was a descriptive prospective study carried out at the Endoscopy Unit of the University College Hospital, Ibadan, Nigeria. A total of 184 African patients had colonoscopy during the study period, 14 were excluded because they had obstructing lesions in the distal colon, two were excluded because caecal intubation was not achieved in them due to technical difficulty and one was excluded due to prior right hemicolectomy. Written informed consents were obtained from all the patients prior to the procedure. Prior to the procedure, patients' demographic data as well as history of prior abdominal or pelvic surgery were recorded. The height and weight of each patient were taken using a stadiometer, and the BMI was calculated by dividing the weight in kilogram by the square of the height in metre. All the patients had bowel preparation which consisted of 3 days of liquid diet, bisacodyl tablets and suppository, as well as oral normal saline $2 \mathrm{~L}$ in the morning and evening a day before the procedure, and another $2 \mathrm{~L}$ early in the morning on the day of the procedure. Shortly before the procedure, patients were administered intravenous midazolam 2.5-5 mg and pentazocine $15-30 \mathrm{mg}$. Colonoscopy was performed using an Olympus Exera III Videocolonoscope (CF HQ190L). All the colonoscopies were performed by one examiner, whose yearly volume is about 500 procedures. The vital signs of the patients were monitored pre, intra and postprocedure using a Multiparameter Monitor ((Marathon Z, Health-care Equipment and Supplies co. Ltd. UK). CIT was measured from the time of insertion of the colonoscope into the anal canal to the time when the base of the caecum was intubated (when the appendiceal opening and the ileocaecal valve were identified), using the digital clock with seconds on the screen of the videoscope monitor. Bowel preparation was adjudged as poor if there was a significant amount of semisolid/solid faeces; satisfactory if there was only clear liquid or a small amount of semisolid faeces; good if only a small amount of clear liquid was seen in the colonic lumen. The data were analysed using SPSS V.17.0 (SPSS Inc., Chicago, Illinois,USA). Means were used to express continuous variables and the means were compared where appropriate. Univariate and multivariate analyses were also performed at a significant level of $\mathrm{p}<0.05$.

\section{RESULTS}

A total of 167 patients comprising 99 (59.3\%) males and $68(40.7 \%)$ females were studied, with a male to female ratio of 1.5:1. The mean age of the patients was 55.6 \pm 13.4 years with a range of $21-82$ years. The results showed that $121(72.5 \%)$ patients were less than 65 years of age, while $46(27.5 \%)$ were older than 65 years of age, but there was no significant difference between these two age groups $(\mathrm{p}=0.37)$. Prior abdominal or pelvic surgery was present in $25(15.1 \%)$ patients, and the most frequent surgeries were appendectomy in 6 $(3.6 \%)$, herniorrhaphy in $5(3.0 \%)$ and hysterectomy in $4(2.4 \%)$ patients. Bowel preparation was adjudged to be good, satisfactory and poor in $80(47.9 \%), 57(34.1 \%)$ and $30(18.0 \%)$ patients, respectively. Again, there was no significant difference among these groups $(p=0.09)$. The bowel preparation was evaluated before washing. However, in those with poor bowel preparation, the mucosa was adequately washed and inspected on withdrawal so as to detect any polyp. The time spent on mucosal washing did not affect the CIT, because this was done during withdrawal in the patients with poor bowel preparation. The results also showed that additional manoeuvres like abdominal pressure and/or change to a supine posture were required in $77(46.1 \%)$ patients, while $90(53.9 \%)$ patients did not require such manoeuvres. There was a significant difference in CIT between these two groups in terms of requirement for additional manoeuvres during colonoscopy $(\mathrm{p}=0.00)$. The mean weight, height and body mass index (BMI) of the patients were $73.0 \pm 15.2 \mathrm{~kg}, 1.69 \pm 0.11 \mathrm{~m}$ and 25.5 $\pm 5.3 \mathrm{~kg} / \mathrm{m}^{2}$, respectively. Analysis of the BMI showed that $11(6.6 \%)$ patients had low BMI, $69(41.3 \%)$ had normal BMI and $87(52.1 \%)$ had increased BMI (figure 1).

The mean CIT of the procedures was $912.5 \pm 477.1 \mathrm{~s}$ $(15.2 \pm 7.9 \mathrm{~min})$ with a range of $180-3180 \mathrm{~s}(3-53 \mathrm{~min})$. It was observed that, the mean CIT was more prolonged in those older than 65 years of age, in males and in those with prior abdominal/pelvic surgery, although no significance difference was observed among the groups.

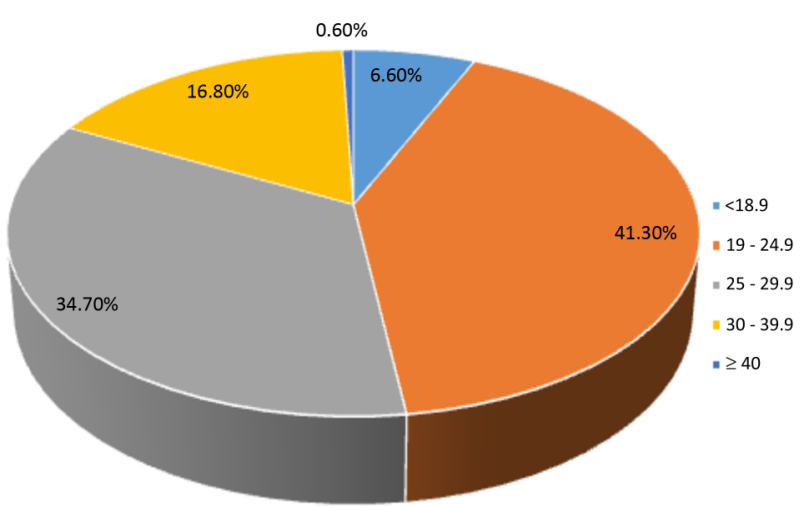

Figure 1 Distribution of BMI among the patients. BMI, body mass index. 
Among the patients with previous surgery, the lowest mean CIT was observed in the patients who had exploratory laparotomy (table 1).

The univariate analysis showed that good bowel preparation and non-usage of additional manoeuvres during the procedures were significantly associated with shorter CIT (table 1). With respect to BMI, the mean CIT was observed to decrease with increasing BMI, except among those with BMI between $30-39.9 \mathrm{~kg} / \mathrm{m}^{2}$ in whom the CIT actually increased (table 1) However, multivariate logistic regression analysis showed that BMI and use of additional manoeuvres during the procedures were significantly associated with CIT. The analysis showed the coefficient of the BMI and use of additional manoeuvres to be negative, which implies that increased BMI and non-usage of additional manoeuvres independently reduced CIT (table 2).

\section{DISCUSSION}

In this study, the mean CIT observed was higher than the mean reported by Krishnan et at and the median time reported by Hsieh et $a l^{2}$ This could be related to the geographical and racial variations in the length of the colon. It has been reported that Africans have a significantly longer sigmoid colon, as well as a narrower sigmoid mesocolon with a significantly high incidence of redundant sigmoid colon compared to the Caucasians. ${ }^{7}$ In another study by Madiba $\mathrm{et} a l^{8}$ the entire colon length was found to be significantly longer in Africans. Older age was found to be associated with prolonged CIT in this study. This was also observed in previous studies. ${ }^{2} 69$ It has been reported that older age is associated with increased colon length, decreased colon elasticity, as well as increased colon laxity. ${ }^{10}$ All these factors can predispose to loop formation and thereby increase CIT.

With respect to gender, male gender was found to be associated with prolonged CIT in our study. This is in contrast to earlier studies where female gender was found to be associated with prolonged CIT. ${ }^{2} 46{ }^{11}$ This finding could be due to the fact that there were more males compared to females in the present study, whereas in most of these earlier studies the converse was the

Table 1 Distribution of predictors of caecal intubation time (CIT)

\begin{tabular}{|c|c|c|c|}
\hline Variables & n (\%) & Mean CIT (seconds) & p Value \\
\hline \multicolumn{4}{|l|}{ Gender } \\
\hline Male & 99 (59.3) & $913.86 \pm 453.28$ & \multirow[t]{2}{*}{0.964} \\
\hline Female & $68(40.7)$ & $910.44 \pm 513.33$ & \\
\hline \multicolumn{4}{|l|}{ Age (years) } \\
\hline$<65$ & $121(72.5)$ & $886.73 \pm 470.81$ & \multirow[t]{2}{*}{0.260} \\
\hline$\geq 65$ & 46 (27.5) & $980.08 \pm 492.19$ & \\
\hline \multicolumn{4}{|l|}{ Prior abdominal/pelvic surgery } \\
\hline Yes & $25(15.1)$ & $1033.80 \pm 581.40$ & \multirow[t]{2}{*}{0.167} \\
\hline No & $141(84.9)$ & $890.11 \pm 456.89$ & \\
\hline \multicolumn{4}{|l|}{ Use of additional manoeuvres } \\
\hline Yes & $77(46.1)$ & $1132.75 \pm 551.31$ & \multirow[t]{2}{*}{0.000} \\
\hline No & $90(53.9)$ & $724.0 \pm 295.24$ & \\
\hline \multicolumn{4}{|l|}{ Weight } \\
\hline$<72.9$ & $83(49.7)$ & $914.39 \pm 409.58$ & \multirow{2}{*}{0.959} \\
\hline$>72.9$ & $84(50.3)$ & $910.57 \pm 538.12$ & \\
\hline \multicolumn{4}{|l|}{ Height } \\
\hline$<1.69$ & $80(47.9)$ & $913.80 \pm 445.88$ & \multirow[t]{2}{*}{0.973} \\
\hline$>1.69$ & $87(52.1)$ & $911.24 \pm 506.74$ & \\
\hline \multicolumn{4}{|l|}{ Body mass index } \\
\hline$<18.9$ & $11(6.6)$ & $951.18 \pm 251.01$ & \multirow[t]{5}{*}{0.869} \\
\hline $19-24.9$ & 69 (41.3) & $915.91 \pm 455.95$ & \\
\hline $25-29.9$ & $58(34.7)$ & $879.26 \pm 502.33$ & \\
\hline $30-39.9$ & $28(16.8)$ & $969.89 \pm 556.03$ & \\
\hline$\geq 40$ & $1(0.6)$ & 567.00 & \\
\hline \multicolumn{4}{|l|}{ Type of abdominal/pelvic surgery } \\
\hline Appendectomy & $6(3.6)$ & $910.83 \pm 275.65$ & \multirow[t]{9}{*}{0.573} \\
\hline Appendectomy, Herniorrhaphy and Prostatectomy & $1(0.6)$ & 826.00 & \\
\hline Caesarean section & $2(1.2)$ & $1460.00 \pm 222.03$ & \\
\hline Exploratory lap & $3(1.8)$ & $484.00 \pm 455.42$ & \\
\hline Haemorrhoidectomy & $2(1.2)$ & $1134.00 \pm 832.97$ & \\
\hline Herniorrhaphy & $5(3.0)$ & $1284.00 \pm 969.92$ & \\
\hline Hysterectomy & $4(2.4)$ & $1222.50 \pm 786$ & \\
\hline Myomectomy & $1(0.6)$ & 880.00 & \\
\hline Prostatectomy & $1(0.6)$ & 877.00 & \\
\hline
\end{tabular}




\begin{tabular}{lrll}
$\begin{array}{l}\text { Table } 2 \\
\text { time }\end{array}$ & Relative effects of variables on caecal intubation \\
\hline Variables & $\boldsymbol{\beta}$ & SE & p Value \\
\hline Age & 0.018 & 0.014 & 0.216 \\
Gender & 0.340 & 0.443 & 0.443 \\
Weight & 0.059 & 0.035 & 0.094 \\
Height & -3.599 & 3.413 & 0.292 \\
Previous surgery (abdominal/ & -0.327 & 0.493 & 0.507 \\
pelvic) & & & \\
Quality of bowel preparation & -0.405 & 0.244 & 0.097 \\
Additional manoeuvre & -1.404 & 0.380 & 0.000 \\
Body mass index & -1.165 & 0.593 & 0.049 \\
\hline
\end{tabular}

case. Gender differences in the distribution of gluteal and visceral fat, as well as the colonic length which favours loop formation in women, have been used to explain the prolonged CIT observed in females in these earlier studies. ${ }^{12}$ It is possible that some of these gender differences in the colon do not apply to blacks. This is supported by the findings of Madiba $e t a l^{7}$ in their study in which no gender difference was observed in the length of the sigmoid colon, as well as the height and width of the sigmoid mesocolon in Africans. In our study, prior abdominal or pelvic surgery was associated with a longer CIT. This is consistent with findings of earlier studies. ${ }^{13}{ }^{14}$ It has been observed that prior abdominal/pelvic surgery, especially abdominal hysterectomy, might make colonoscopy difficult as a result of a fixed and angulated sigmoid colon associated with this surgery. ${ }^{15}$ However, in this study, the most common prior surgery in our patients was appendectomy, and the mean CIT in those who have had this surgery was even lower than in those with prior abdominal hysterectomy. In a study by Takahashi et $a l^{16}$ in Japan, prior hysterectomy was found to predict difficult colonic intubation. However, Waye and Bashkoff ${ }^{17}$ reported no association between caecal intubation and prior abdominal hysterectomy. In this study, the lowest mean CIT was observed in the patients with prior exploratory laparotomy compared to those with other forms of abdominal/pelvic surgery. It is possible that exploratory laparotomy is associated with the formation of more extensive adhesions than other forms of abdominal/pelvic surgery, and that these adhesions may cause the colon to be fixed, thereby reducing loop formation and easing caecal intubation. Another significant observation in our study is the association between the use of additional manoeuvres during colonoscopy and CIT. It was observed that the use of additional manoeuvres prolonged the CIT. This is expected because the time taken to apply these additional measures like abdominal pressure and the change of posture of the patient would definitely add to the time to achieve caecal intubation. In terms of anthropometry, strong correlation had been reported between body height and the length of the colon, ${ }^{18}$ which may in turn affect CIT. However, in our study, no significant correlation was observed between the patients' height or weight and CIT. One other factor that has been reported to be correlated with CIT is the BMI. Some studies have observed lower BMI to be associated with a prolonged CIT. $^{1}{ }^{11}{ }^{19}$ In our study, this trend was also observed except for those patients whose BMI was between $30-39 \mathrm{~kg} / \mathrm{m}^{2}$ in whom the CIT was prolonged. Patients who are overweight and obese are believed to have more visceral fat, which tends to support the colon and minimise formation of loops, ${ }^{20}$ thereby shortening CIT. Also, overweight and obese patients have been reported to have shorter colons, ${ }^{20}$ which this may aid faster caecal intubation. However, in the study by Hsieh $e t a l{ }^{2}$ waist circumference was found to better predict difficult caecal intubation compared to BMI. The former is said to reflect visceral fat more accurately than the latter.

Although the expertise of the colonoscopist also influences CIT, depending on whether it was carried out by a fellow in training or a specialist. The effect of this particular factor in this study was very minimal because all the procedures were carried out by a single specialist so as to minimise inter-specialist differences.

One notable limitation of this study was the inability to assess patients' pain tolerance as it contributes to difficult colonoscopy. However, since the patients had sedation and analgesia, the effect of pain tolerance on the overall result was probably insignificant.

In conclusion, this study has shown that older age, male gender, prior abdominal/pelvic surgery, use of additional manoeuvres and lower BMI were associated with prolonged CIT.

Acknowledgements The authors wish to thank all the resident doctors, the nurses and support members of staff of the endoscopy unit of the University College Hospital, Ibadan for their contribution to the success of this research work.

Competing interests None declared.

Provenance and peer review Not commissioned; externally peer reviewed.

Data sharing statement No additional data are available.

Open Access This is an Open Access article distributed in accordance with the Creative Commons Attribution Non Commercial (CC BY-NC 4.0) license, which permits others to distribute, remix, adapt, build upon this work noncommercially, and license their derivative works on different terms, provided the original work is properly cited and the use is non-commercial. See: http:// creativecommons.org/licenses/by-nc/4.0/

\section{REFERENCES}

1. Leiberman DA, Weiss DG, Bond JH, et al. Use of colonoscopy to screen asymptomatic adults for colorectal cancer. $N$ Engl J Med 2000;343:162-8.

2. Hsieh $\mathrm{YH}$, Kuo CS, Tseng KC, et al. Factors that predict caecal insertion time during sedated colonoscopy: the role of waist circumference. J Gastroenterol Hepatol 2008;23:215-17.

3. Kim WH, Cho YJ, Park JY, et al. Factors affecting insertion time and patient discomfort during colonoscopy. Gastrointest Endosc 2000;52:600-5.

4. Anderson JC, Messina CR, Cohn W, et al. Factors predictive of difficult colonoscopy. Gastrointest Endosc 2001;54:558-62.

5. Church JM. Complete colonoscopy: how often? And if not, why not? Am J Gastroenterol 1994;89:556-60.

6. Krishnan P, Sofi AA, Dempsey R, et al. Body mass index predicts cecal insertion time: the higher, the better. Dig Endosc 2012;24:439-42. 
7. Madiba TE, Haffajee MR. Sigmoid colon morphology in the population groups of Durban, South Africa, with special reference to sigmoid volvulus. Clin Anat 2011;24:441-53.

8. Madiba TE, Haffajee MR, Sikhosana MH. Radiological anatomy of the sigmoid colon. Surg Radiol Anat 2008;30:409-15.

9. Koido S, Ohkusa T, Nakae K, et al. Factors associated with incomplete colonoscopy at a Japanese academic hospital. World $\mathrm{J}$ Gastroenterol 2014;20:6961-7.

10. Sadahiro S, Ohmura T, Yamada Y, et al. Analysis of length and surface area of each segment of the large intestine according to age, sex and physique. Surg Radiol Anat 1992;14:251-7.

11. Bernstein $\mathrm{C}$, Thorn $\mathrm{M}$, Monsees $\mathrm{K}$, et al. A prospective study of factors that determine cecal intubation time at colonoscopy. Gastrointest Endosc 2005;61:72-5.

12. Krotkiewski M, Bjorntorp P, Sjostrom L, et al. Impact of obesity on metabolism in men and women. Importance of regional adipose tissue distribution. J Clin Invest 1983;72:1150-62.

13. Park CH, Lee WS, Joo YE, et al. Sedation-free colonoscopy using an upper endoscope is tolerable and effective in patients with low body mass index: a prospective randomized study. $A m \mathrm{~J}$ Gastroenterol 2006; 101:2504-10

14. Hull T, Church JM. Colonoscopy- how difficult, how painful? Surg Endosc 1994;8:784-7.

15. Chutkan R. Colonoscopy issues related to women. Gastrointest Endosc Clin N Am 2006;16:153-63.

16. Takahashi $\mathrm{Y}$, Tanaka H, Kinjo M, et al. Prospective evaluation of factors predicting difficulty and pain during sedation-free colooscopy. Dis Colon Rectum 2005;48:1295-300.

17. Waye JD, Bashkoff E. Total colonoscopy: is it always possible? Gastrointest Endosc. 1991;37:152-4.

18. Minko E, Pagano A, Caceres N, et al. Human intestinal tract length and relationship with body height. FASEB $J$ 2014;28:916.4.

19. Anderson JC, Gonzalez JD, Messina CR, et al. Factors that predict incomplete colonoscopy: thinner is not always better. $A m \mathrm{~J}$ Gastroenterol 2000;95:2784-7.

20. Khashab MA, Pickhardt PJ, Kim DH, et al. Colorectal anatomy in adults at computed tomography colonography: Normal distribution and the effect of age, sex, and body mass index. Endoscopy 2009;41:674-8. 